\title{
High-dose methotrexate in ICU patients: a retrospective study
}

\author{
Sandrine Valade ${ }^{1,2^{*}}$, Eric Mariotte ${ }^{1,2}$, Elie Azoulay ${ }^{1,2}$ and Michael Darmon ${ }^{1,2}$
}

\begin{abstract}
Background: High-dose methotrexate (HD-MTX) is commonly used in the treatment of solid tumors and hematological malignancies. Severe toxicities are frequent, leading to organ dysfunction and death. Risk-benefit ratio of using HD-MTX in critically ill patients is unknown. This study aims to describe MTX-induced toxicities and to assess outcome in ICU patients. We conducted a retrospective single-center study conducted in a university hospital ICU between January 2002 and December 2018. Consecutive patients treated by HD-MTX were included.

Results: 33 patients (24 men and 9 women) aged 48 years [34-63], were included. B cell lymphoma had been diagnosed in 31 patients (Burkitt, $n=14$; diffuse large B-cell lymphoma with CNS (central nervous system) involvement, $n=9$; primary CNS lymphoma, $n=5$ ) and T-cell lymphoma in two patients. Patients were mainly admitted for coma $(n=14 ; 42 \%)$ or acute kidney injury $(n=8 ; 24 \%)$. MTX was administered at a median dose of $6.1 \mathrm{~g}$ [5-14]. Fourteen patients had concomitant medication interacting with MTX. Median MTX clearance was 4 days [4-5]. Frequent MTXrelated complication were mucositis $(n=21,64 \%)$, diarrhea $(n=14,44 \%)$ or hepatic failure $(n=15,45 \%)$. During ICU stay, 11 patients experienced acute kidney injury (KDIGO stage 3 [2-3]). Two patients received carboxypeptidase and three underwent dialysis. Overall, 19 patients (57\%) required mechanical ventilation, 10 (30\%) vasopressors. Hospital mortality was $30 \%(n=10)$. Cox model identified MTX concentration $24 \mathrm{~h}$ after administration higher than $4.6 \mu \mathrm{mol} / \mathrm{L}$ as associated with hospital mortality (HR 6.7; 95\% Cl 1.6-27.3).

Conclusions: To our knowledge, this is the first study assessing characteristics and outcome of critically ill patients receiving HD-MTX. MTX concentration at $\mathrm{H} 24$ was associated with hospital mortality. Despite underlying malignancy, ICU support of these patients was associated with a meaningful survival.
\end{abstract}

Keywords: Methotrexate, Acute kidney injury, Outcome, Hematological malignancies, Drug-related side effects, Antineoplastic agents

\section{Background}

Intravenous high-dose methotrexate (HD-MTX) is commonly used in the treatment of hematological malignancies, particularly in high-grade lymphomas [1]. MTX-related toxicities are common, leading to organ dysfunction that can be very severe, and rarely to death [1]. Acute kidney injury (AKI) is frequently reported, affecting up to $35 \%$ of adult patients, mostly in relation

\footnotetext{
${ }^{*}$ Correspondence: sandrine.valade@aphp.fr

${ }^{1}$ Medical ICU, APHP, Saint-Louis Hospital, Paris, France

Full list of author information is available at the end of the article
}

with intratubular crystal formation or endothelial injuries $[1,2]$.

This drug requires a close monitoring and management of MTX-related toxicities relies mostly on preventing measures $[1,3]$. AKI is frequent in critically ill patients with newly diagnosed high-grade hematological malignancies [4] and is associated with a high level of frailty. Whether ICU patients may be considered eligible for HD-MTX and risk-benefit ratio in this setting has never been assessed.

This primary objective of this study was to assess outcome in critically ill patients requiring HD-MTX
Springer Open

(C) The Author(s) 2020. This article is licensed under a Creative Commons Attribution 4.0 International License, which permits use, sharing, adaptation, distribution and reproduction in any medium or format, as long as you give appropriate credit to the original author(s) and the source, provide a link to the Creative Commons licence, and indicate if changes were made. The images or other third party material in this article are included in the article's Creative Commons licence, unless indicated otherwise in a credit line to the material. If material is not included in the article's Creative Commons licence and your intended use is not permitted by statutory regulation or exceeds the permitted use, you will need to obtain permission directly from the copyright holder. To view a copy of this licence, visit http://creativeco mmons.org/licenses/by/4.0/. 
infusion. Secondary objectives were to describe toxicities and risk factors of poor outcome in this setting.

\section{Methods}

\section{Patients and data collection}

We retrospectively reviewed the medical charts of all consecutive adult patients admitted to the intensive care unit of one university hospital from January, 1st, 2002 to December 31th, 2018, and who received HD-MTX for hematological malignancy or solid tumor. There were no exclusion criteria.

HD-MTX was defined by a single intravenous infusion greater than $500 \mathrm{mg} / \mathrm{m}^{2}$. The different stages of toxicity were defined according to the CTCAE [5]. MTX complete elimination was considered when MTX concentration was lower than $0.1 \mu \mathrm{mol} / \mathrm{L}$.

This study was approved by a local ethic committee (Société de Réanimation de Langue Française, CE SRLF 19-01). According to French law, need for informed consent was waived.

\section{Statistical analysis}

Results are described as medians and interquartile ranges (IQR) for quantitative variables and numbers and percentages for qualitative variables. We used a non-parametric Wilcoxon tests and Fisher exact tests for baseline univariate comparisons between two groups.

Cox regression model were performed to identify factors associated with hospital mortality. Variable selection was performed on a stepwise fashion, backward conditional model according to $P$ value with entry $P$ value of 0.2 and critical removal $P$ value of 0.1 . Proportional hazard assumption was checked in the final model.

All tests were two-sided, and $P$ values less than 0.05 were considered significant. Analyses were done using $R$ software version 4.3.4 (R Project for Statistical Computing, Wien, Austria) and with 'Survival' packages.

\section{Results}

33 patients ( 24 men, 9 women) were included with a median age of 48 years [34-63]. All the patients had aggressive hematological malignancies and most of them $(n=31 / 33)$ had not received any antitumor treatment. B-cell lymphoma had been diagnosed in 31 patients (Burkitt $[n=14]$; diffuse large B-cell lymphoma with CNS involvement $[n=9]$; primary CNS lymphoma $[n=5]$; primary effusion lymphoma $[n=2]$; intravascular lymphoma $[n=1]$ ) and T-cell lymphoma in two patients. Twelve (36\%) had HIV infection, three had hypertension and one patient was diabetic (Table 1).

Patients were mainly admitted to the ICU for coma $(n=14 ; 42 \%)$ or acute kidney injury $(n=8 ; 24 \%)$. Five (15\%) patients presented respiratory failure and only
Table 1 Characteristics of patients at study inclusion

\begin{tabular}{|c|c|c|c|}
\hline$N(\%)$ or median (IQR) & $\begin{array}{l}\text { Survivors } \\
n=23\end{array}$ & $\begin{array}{l}\text { Non survivors } \\
n=10\end{array}$ & $P$ value \\
\hline \multicolumn{4}{|l|}{ Demographics } \\
\hline Age (years) & $38[31-51]$ & $63.5[51-69]$ & 0.013 \\
\hline Male gender & $14(61 \%)$ & $10(100 \%)$ & 0.058 \\
\hline \multicolumn{4}{|l|}{ Comorbidities } \\
\hline HIV infection & $9(39 \%)$ & $3(12 \%)$ & 0.914 \\
\hline Hypertension & $2(8.7 \%)$ & $2(20 \%)$ & 0.74 \\
\hline Diabetes & $1(4.3 \%)$ & 0 & 1 \\
\hline Hematological malignancy & & & 0.52 \\
\hline B cell lymphoma & $21(91 \%)$ & $10(100 \%)$ & \\
\hline Burkitt lymphoma & 10 & 4 & \\
\hline $\begin{array}{l}\text { Diffuse large B cell lym- } \\
\text { phoma }\end{array}$ & 5 & 4 & \\
\hline Primary CNS lymphoma & 4 & 1 & \\
\hline $\begin{array}{l}\text { Primary effusion lym- } \\
\text { phoma }\end{array}$ & 2 & 0 & \\
\hline Intravascular lymphoma & 0 & 1 & \\
\hline T cell lymphoma & $2(8.7 \%)$ & 0 & \\
\hline Reason for ICU admission & & & 0.575 \\
\hline Neurological disorders & $10(43.5 \%)$ & $4(40 \%)$ & \\
\hline Acute kidney injury & $6(26 \%)$ & $2(20 \%)$ & \\
\hline Acute respiratory distress & $3(13 \%)$ & $2(20 \%)$ & \\
\hline Cardiovascular failure & 0 & $1(10 \%)$ & \\
\hline Other & $4(17 \%)$ & $1(10 \%)$ & \\
\hline \multicolumn{4}{|l|}{ Biological tests } \\
\hline Creatinine $(\mu \mathrm{mol} / \mathrm{L})$ & 55 [39-72] & $56[47-86]$ & 0.26 \\
\hline Albumin $(g / L)$ & $36[31-38]$ & $27.5[24-31.8]$ & 0.045 \\
\hline Bilirubin $(\mu \mathrm{mol} / \mathrm{L})$ & $7.8[6-13.2]$ & $12[6.9-13.4]$ & 0.329 \\
\hline Leukocytes (G/L) & $7.7[5.1-8.9]$ & $7.1[1.5-10.0]$ & 0.78 \\
\hline Hemoglobin (g/dL) & $9.7[8.3-12.5]$ & $9.0[8.1-10.3]$ & 0.32 \\
\hline Platelets (G/L) & 195 [150-255] & 166 [111-272] & 0.49 \\
\hline SOFA score & $2[1-5]$ & $6[4-9.5]$ & 0.022 \\
\hline \multicolumn{4}{|l|}{ Treatments in the ICU } \\
\hline Mechanical ventilation & $10(43.5 \%)$ & $9(90 \%)$ & 0.036 \\
\hline Vasopressors & $3(13 \%)$ & $7(70 \%)$ & 0.004 \\
\hline Renal replacement therapy & 0 & $3(30 \%)$ & 0.036 \\
\hline
\end{tabular}

HIV human immunodeficiency virus, SOFA score Sepsis-related Organ Failure Assessment, ICU intensive care unit

one patient had shock. Fifteen patients had a Glasgow Coma Scale of 12 or below and all except one presented with neurologic involvement related to lymphoma. SOFA score was 4 [1-5] at admission and 2 [1-5] the day of MTX infusion. All the patients except one presented a normal renal function at baseline (median serum creatinine $=55 \mu \mathrm{mol} / \mathrm{L}$ [41-74]), 12 experienced AKI episode in the last 3 months, including 8 requiring renal replacement therapy (RRT) (Table 1).

MTX was administered at a median dose of $3.4 \mathrm{~g} / \mathrm{m}^{2}$ [2.6-7.4] and the median delay between ICU admission 
and MTX infusion was 4 days [2-7]. Twenty patients (61\%) received concomitant intrathecal MTX. Other most commonly used chemotherapy drugs were cyclophosphamide $(n=23)$, doxorubicin $(n=23)$ and vincristine $(n=21)$. Median body mass index (BMI) was 24.9 [21.4-27.1] and median albumin level was $33 \mathrm{~g} / \mathrm{L}$ [26-37]. Median creatinine level was $55 \mu \mathrm{mol} / \mathrm{L}$ [41-74] on the day of MTX administration. All patients received parenteral hyperhydration and alkalinization. Only 6 patients failed to achieve urine $\mathrm{pH}$ above 7.5 at least once within the first $24 \mathrm{~h}$ following MTX infusion. Folinic acid rescue was started $24 \mathrm{~h}$ after MTX infusion for all patients except one. The median time required until a complete elimination of MTX was 4 days [4-5]. Fourteen patients had concomitant medication interacting with MTX, mostly piperacillin-tazobactam $(n=8)$, protonpump inhibitors $(n=9)$ or levetiracetam $(n=4)$. Seven patients presented serous effusions that required fluid removal (pleural effusions, $n=6$ and ascites, $n=1$ ).
More than $80 \%$ of patients $(n=27)$ experienced at least one MTX-related toxicity (Table 2). The most frequent MTX-related complications were mucositis $(n=21,64 \%$; median CTCAE grade $3[2-4])$, diarrhea $(n=14,44 \%$; median CTCAE grade 2 [2-3]) or liver tests disturbance $(n=15,45 \%$; median CTCAE grade $3[2-4])$. Following MTX infusion, the majority of patients developed neutropenia $(n=26)$ and acquired bacterial infections $(n=17,51 \%)$. During ICU stay, one-third of patients $(n=11)$ experienced acute kidney injury (KDIGO stage 2.5 [2-3]) and median onset was reached 3.5 days [2-5] after MTX infusion. Eight patients also received concomitant nephrotoxic agents including contrast media $(n=3)$ and aminoglycosides $(n=3)$. Renal toxicity and MTX overdosage lead to carboxypeptidase G2 administration in 2 patients and need for RRT initiation in three.

Overall, 19 patients (57\%) required mechanical ventilation, within a median time of 5 [1-12] days prior to MTX administration, and 10 (30\%) vasopressors. Median

Table 2 MTX-related toxicities and outcome

\begin{tabular}{|c|c|c|c|}
\hline$N(\%)$ or median (IQR) & $\begin{array}{l}\text { Survivors } \\
n=23\end{array}$ & $\begin{array}{l}\text { Non survivors } \\
n=10\end{array}$ & $P$ value \\
\hline \multicolumn{4}{|l|}{ MTX infusion } \\
\hline Median dose (g) & $7.4[4.9-14]$ & $5.85[5.1-10.5]$ & 0.814 \\
\hline Time since ICU admission (days) & $4[1-7]$ & $4[2.2-8.7]$ & 0.335 \\
\hline \multicolumn{4}{|l|}{ Interacting medications } \\
\hline Mean number of medications (sd) & $0.69(0.89)$ & $0.8(0.92)$ & 0.578 \\
\hline Piperacillin-tazobactam & 4 & 4 & \\
\hline Proton-pump inhibitors & 6 & 3 & \\
\hline Levetiracetam & 4 & 0 & \\
\hline MTX-related complications & $18(78 \%)$ & $9(90 \%)$ & 0.76 \\
\hline \multicolumn{4}{|l|}{ Including ${ }^{a}$} \\
\hline Acute kidney injury & $7(30 \%)$ & $4(40 \%)$ & \\
\hline Mucositis & $15(65 \%)$ & $6(60 \%)$ & \\
\hline Diarrhea & $6(26 \%)$ & $8(80 \%)$ & \\
\hline Liver tests disturbances & $11(48 \%)$ & $4(40 \%)$ & \\
\hline \multicolumn{4}{|l|}{ MTX concentrations ( $\mu \mathrm{mol} / \mathrm{L})$} \\
\hline MTX H24 & $3.1[1.5-5.62]$ & $19.5[6.2-29.4]$ & 0.052 \\
\hline MTX H36 & $5.4[3-7.7]$ & $16.7[2.23-44.2]$ & 0.643 \\
\hline MTX H48 & $0.4[0.3-0.7]$ & $1.6[0.6-5.9]$ & 0.103 \\
\hline MTX H72 & $0.3[0.1-0.4]$ & $0.6[0.2-3.9]$ & 0.143 \\
\hline MTX H96 & $0.07[0.02-0.12]$ & $0.34[0.26-1.25]$ & 0.013 \\
\hline \multicolumn{4}{|l|}{ Specific treatments } \\
\hline Median dose of folinic acid rescue (mg) & 200 [200-200] & 320 [200-800] & 0.003 \\
\hline Carboxypeptidase & $1(4.3 \%)$ & $2(20 \%)$ & 0.436 \\
\hline \multicolumn{4}{|l|}{ Outcomes } \\
\hline Length of ICU stay (days) & $10[6-18.5]$ & $19.5[10.7-25]$ & 0.16 \\
\hline Length of hospital stay & $64.5[37-103]$ & $36[29-72.7]$ & 0.13 \\
\hline End of life decision & $2(9 \%)$ & $9(90 \%)$ & $<0.001$ \\
\hline
\end{tabular}

MTX methotrexate, ICU intensive care unit

a Some patients experienced several MTX-related complications 
length of ICU stay was 11 days [6-24]. Overall, ICU and hospital mortality were $18 \%(n=6)$ and $30 \%(n=10)$, respectively. Eighteen patients (55\%) were alive 6 months after ICU discharge among whom, 15 (83\%) had a complete and sustained hematological remission.

In univariate analysis, mortality was associated with older age (median age 63.5 years [51.25-68.75] vs 38 years [31-51.5, $p=0.013]$ ), lower albumin level $(27.5 \mathrm{~g} / \mathrm{L}$ [24-31.75] vs $36 \mathrm{~g} / \mathrm{L}$ [31-38], $p=0.045)$, and higher severity as assessed by SOFA score (6 [4.25-9] vs 2 [1-5], $p=0.022$ ).

After adjustment for patients' severity, MTX concentration $24 \mathrm{~h}$ after administration was independently associated with hospital mortality (HR if concentration above $4.6 \mu \mathrm{mol} / \mathrm{L}$ 6.7; 95\% CI 1.6-27.3) (Table 3) (Fig. 1). In non-survivors, creatinine levels were significantly higher the day after MTX administration $(p=0.0017)$ and during the first week ( $p=0.026)$ (Fig. 2).

\section{Discussion}

To our knowledge, this is the first study assessing benefits and risk of HD-MTX in critically ill patients. This study underlines the high rate of risk factors for HD-MTX toxicity and the high rate of MTX-related toxicities. Our results also underline that 6-month survival may be obtained in $55 \%$ of the patients and that complete remission may be obtained in $83 \%$ of them.

In the literature, classically 2 to $12 \%$ of non-ICU patients are reported to develop renal failure following HD-MTX. In fact up to $35 \%$ of patients experienced AKI, with a large heterogeneity according to the studied population, HD-MTX protocols and AKI criteria [6]. In critically ill patients, AKI incidence also varies widely from 22 to $67 \%$, discrepancies mainly relying on the definition applied [7]. In our study, we found a high rate of AKI as one in three patients experienced renal failure. This is in line with a previous study in which the authors showed that two-thirds of critically ill patients with newly diagnosed aggressive hematological malignancies developed AKI [4]. Our results highlight that MTX-induced renal toxicity is very frequent in ICU patients.

Survival of patients with hematological malignancies has improved over the past decades and an increasing number of patients may need ICU admission [8]. In

Table 3 Variables associated with hospital mortality after adjustment

\begin{tabular}{llll}
\hline Variables & Hazard ratio & $\begin{array}{l}\mathbf{9 5 \%} \\
\text { confidence } \\
\text { interval }\end{array}$ & $\boldsymbol{P}$ value \\
\hline MTX at H24 (4.6-84.8) & 6.7 & $(1.62-27.3)$ & 0.008 \\
SOFA score & 1.07 & $(0.89-1.27)$ & 0.47 \\
\hline
\end{tabular}
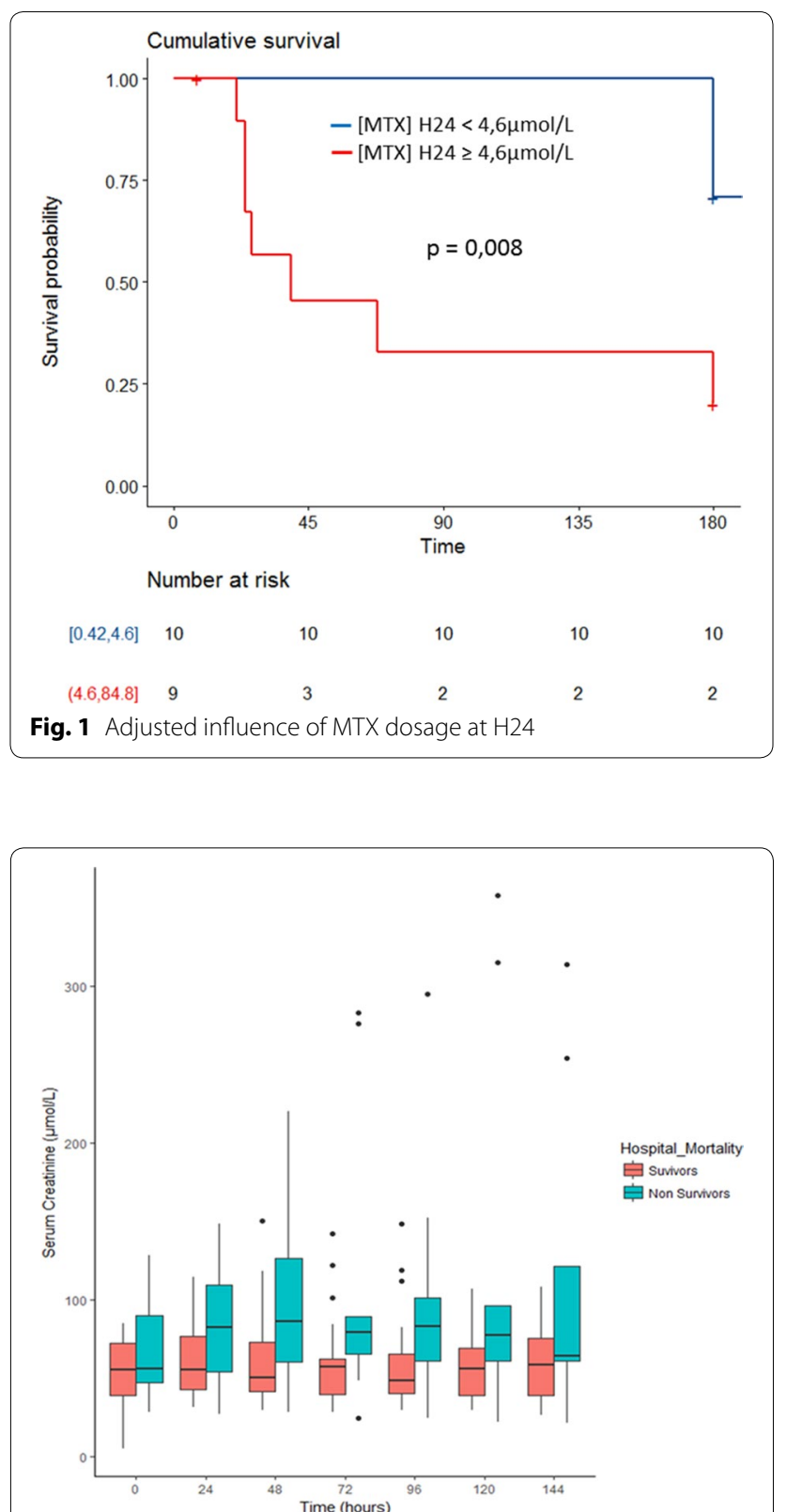

Fig. 2 Relationship between creatinine and hospital mortality within the first week after MTX infusion

previous studies in cancer patients receiving chemotherapy in the intensive care unit, hospital mortality is reported around 40\% [9]. Our study, concurrently suggests the feasibility of HD-MTX in this setting, demonstrating that despite the high toxicity rate, a 6-month survival rate of $55 \%$ may be achieved, the majority of survivors achieving complete remission.

Dose-toxicity relationship of MTX has been descried previously. The most commonly used threshold is a concentration greater than $10 \mu \mathrm{mol} / \mathrm{L} 24 \mathrm{~h}$ after MTX infusion or greater than $1 \mu \mathrm{mol} / \mathrm{L}$ at $\mathrm{H} 48$ [3]. Evans et al. [10] 
previously demonstrated that values above $10 \mu \mathrm{mol} / \mathrm{L}$ $24 \mathrm{~h}$ after the start of MTX infusion were associated with an increased risk of toxicity. As no published data exist in ICU patients, optimal early MTX concentrations predicting the outcome remain unknown.

This study suffers however several limitations. First, due to its retrospective design, exhaustivity of data was limited. Thus, exact assessment of optimal MTX concentration predicting poor outcome could not be assessed. Second, the small sample size led to limited statistical power, negative findings needing to be interpreted cautiously. Moreover, patients deemed eligible to HD-MTX infusion were likely to be selected according to performance status and clinical severity. Despite these limits, our study demonstrates feasibility of HD-MTX with meaningful chances of long-term survival and complete remission.

\section{Conclusion}

This study demonstrates feasibility of HD-MTX in a selected group of critically ill cancer patients. Although the toxicity rate was high, long-term survival was achieved in more than half of the patients and complete remission was achieved in most of these later. Additional studies are needed to allow better identification of patients at high risk of toxicity.

\section{Supplementary information}

Supplementary information accompanies this paper at https://doi. org/10.1186/s13613-020-00693-5.

\section{Additional file 1. Additional materials.}

Additional file 2: Table S1. Standard folinic acid rescue protocol (adapted from T Balloy et al. Modalités de prise en charge des intoxications aiguës par le méthotrexate haute dose. Journal de Pharmacie Clinique. 2007;26(4):253-260. doi:10.1684/jpc.2007.0070).

Additional file 3: Table S2. Criteria for carboxypeptidase use according to the French National Agency for Medicines and Health Products Safety.

\section{Abbreviations}

AKI: Acute kidney injury; BMI: Body mass index; CNS: Central nervous system; CTCAE: Common Terminology Criteria for Adverse Events; HD-MTX: High-dose methotrexate; ICU: Intensive care unit; MTX: Methotrexate; SOFA: Score, sepsisrelated organ failure assessment.

\section{Acknowledgements}

None.

\section{Authors' contributions}

$\mathrm{MD}$ is the guarantor for the content of the manuscript, including the data and analysis. SV, EM, EA, MD contributed substantially to the study design, data analysis and interpretation, and the writing of the manuscript. SV, REM, EA, MD contributed substantially to patients recruitment, collecting data and manuscript revision. All authors read and approved the final manuscript.
Funding

No part of the work presented has received financial support from any source.

\section{Availability of data and materials}

The dataset supporting the conclusions of this article is included within the article (and its Additional files 1, 2, and 3).

\section{Ethics approval and consent to participate}

This study was approved by a local ethic committee (commission d'éthique de la Société de Réanimation de Langue Française, CE 19-01). At ICU admission, patients and relatives receive a leaflet informing them of the existence of clinical studies in the ward and the collection of data with the possibility of declining the use of these data.

\section{Consent for publication}

Not applicable

\section{Competing interests}

The authors declare that they have no competing interests.

\section{Author details}

${ }^{1}$ Medical ICU, APHP, Saint-Louis Hospital, Paris, France. ${ }^{2}$ Université de Paris, Paris, France.

Received: 18 February 2020 Accepted: 4 June 2020

Published online: 13 June 2020

\section{References}

1. Howard SC, McCormick J, Pui C-H, Buddington RK, Harvey RD. Preventing and managing toxicities of high-dose methotrexate. Oncologist. 2016;21(12):1471-82.

2. Garneau AP, Riopel J, Isenring P. Acute methotrexate-induced crystal nephropathy. N Engl J Med. 2015;373(27):2691-3.

3. Widemann BC, Adamson PC. Understanding and managing methotrexate nephrotoxicity. Oncologist. 2006;11(6):694-703.

4. Canet E, Zafrani L, Lambert J, Thieblemont C, Galicier L, Schnell D, et al. Acute kidney injury in patients with newly diagnosed high-grade hematological malignancies: impact on remission and survival. PLOS ONE. 2013;8(2):e55870.

5. Common Terminology Criteria for Adverse Events (CTCAE) | Protocol Development | CTEP [Internet]. https://ctep.cancer.gov/protocolDevelop ment/electronic_applications/ctc.htm. Accessed 8 Oct 2019.

6. Jahnke K, Korfel A, Martus P, Weller M, Herrlinger U, Schmittel A, et al. High-dose methotrexate toxicity in elderly patients with primary central nervous system lymphoma. Ann Oncol Off J Eur Soc Med Oncol. 2005;16(3):445-9.

7. Schetz M, Darmon M. Measuring acute kidney injury around the world: are we using the right thermometer (and adequately)? Intensive Care Med. 2015;41(10):1857-9.

8. Darmon M, Bourmaud A, Georges Q, Soares M, Jeon K, Oeyen S, et al. Changes in critically ill cancer patients' short-term outcome over the last decades: results of systematic review with meta-analysis on individual data. Intensive Care Med. 2019:45(7):977-87.

9. Darmon M, Thiery G, Ciroldi M, de Miranda S, Galicier L, Raffoux E, et al. Intensive care in patients with newly diagnosed malignancies and a need for cancer chemotherapy. Crit Care Med. 2005;33(11):2488-93.

10. Evans WE, Pratt CB, Taylor RH, Barker LF, Crom WR. Pharmacokinetic monitoring of high-dose methotrexate. Early recognition of high-risk patients. Cancer Chemother Pharmacol. 1979;3(3):161-6.

\section{Publisher's Note}

Springer Nature remains neutral with regard to jurisdictional claims in published maps and institutional affiliations. 